\title{
Breech presentation at term: outcomes and mode of delivery in a tertiary care teaching hospital In South India
}

\author{
Liji David, Anuja Abraham*, Preethi Navaneethan, Annie Regi
}

Department of Obstetrics and Gynecology, Christian Medical College Hospital, Vellore, Tamil Nadu, India

Received: 16 July 2019

Revised: 05 September 2019

Accepted: 09 September 2019

*Correspondence:

Dr. Anuja Abraham,

E-mail: abrahamanuja@gmail.com

Copyright: (c) the author(s), publisher and licensee Medip Academy. This is an open-access article distributed under the terms of the Creative Commons Attribution Non-Commercial License, which permits unrestricted non-commercial use, distribution, and reproduction in any medium, provided the original work is properly cited.

\begin{abstract}
The aim of this study was to study the outcomes of all patients who presented with breech presentation at term ( $\geq 37$ weeks), to assess what percentage of patients were offered External cephalic version (ECV), the rates of success of the procedure and the rates of vaginal delivery following successful ECV. It was a retrospective study of 669 patients diagnosed with breech at term, their clinical records were retrieved and data like age, BMI, parity, type of breech and scan findings noted. ECV was done in 256 patients and was successful in $35.5 \%$ of women with $51.1 \%$ being multigravidas and $26.8 \%$ in primigravidas. $76.9 \%$ of women with successful ECV delivered vaginally. There was no significant fetal or maternal morbidity documented as a result of ECV in this study.
\end{abstract}

Keywords: Assisted breech delivery, Caesarean section, Complete breech, External cephalic version, Frank breech, Successful ECV

\section{INTRODUCTION}

Breech presentation refers to the position of the fetus in the uterus with the buttocks occupying the lower segment and the head in the fundus of the uterus. At term, the incidence of breech position is around 3\%-4\%, 7-16\% at 32 weeks and around $25 \%$ at 28 weeks and lesser. ${ }^{1}$ At term the occurrence of breech can be due to chance but the most common cause for a breech presentation is prematurity and other causes are uterine anomalies, congenital fetal anomalies, fetal aneuploidies, tumours occupying lower segment of the uterus, placental abnormality like placenta praevia, multiple pregnancy, fetal neurological disorders, alteration in the liquor volume and multiparity. The frequency of breech is also higher if in prior pregnancies the presentation was breech and the risk increases to $9 \%$ with one and $25 \%$ with two previous breech respectively. ${ }^{2}$
There are three main types of breech presentation:

- Frank or extended breech-which is the most common, incidence being around $50-70 \%$ at term. In this type the legs are extended at the knees and flexed at the hip

- Complete breech - in which the legs are flexed both at the hips and at the knees, is found in 5-10\% at term

- Incomplete breech - one or both hips are not flexed with the foot presenting, incidence around $10-30 \%$ at term.

The current management in most centres for breech presentation at term is a planned caesarean section. Some offer an external cephalic version (ECV) and if it fails, proceed with an elective caesarean section. The practice of having a trial of a vaginal breech delivery has declined over the past few years. The reason for this is the increased perinatal, neonatal mortality and severe 
neonatal morbidity associated with a vaginal breech delivery as reported in the Term Breech Trial. ${ }^{3}$ However, caesarean sections are not free of maternal morbidity and studies on long term complications are limited. ${ }^{4}$ Hence the option of an ECV should be offered to all patients with a breech presentation at term, if not contraindicated. This procedure involves lifting the buttocks of the fetus from the lower segment, flexing the head at the same time and rotating the fetus such that the head comes to occupy the lower segment. It is done in places where there are facilities for emergency caesarean section. The reported success of this procedure by several authors range from $30-50 \% .^{5,6}$ however there are studies that quote success rates as high as $60-70 \%$. $^{7}$

In our institution, the practice is to provide all patients with breech presentation at term the choice of an ECV. The procedure is done under ultrasound guidance after the administration of a tocolytic (injection terbutaline). A second attempt of ECV is done, if the first trial fails, provided the patient is willing. The patient is posted for an elective caesarean section at 39 weeks of gestation if ECV fails in one or two attempts. The option of a trial of vaginal breech delivery is not given. Although ECV is being offered, the rates of success of the procedure, the numbers who declined from participation and rates of vaginal delivery following a successful ECV have not been evaluated.

The objectives of this study were to analyse what percentage of breech pregnancies diagnosed at term were offered ECV and in what percentage the diagnosis of breech was missed. To evaluate what percentage of patients with successful ECV had vaginal delivery.

\section{METHODS}

The study was retrospective and conducted in a large tertiary care teaching hospital in South India which has around 13500 to 14500 deliveries in a year. The antenatal records of all the patients diagnosed with breech presentation at term from January 2016 to December 2017 were retrieved. A total of 669 patients with breech presentation at term were identified from the electronic data base. Their antenatal charts were obtained and relevant information like age, BMI, obstetric score, gestational age at delivery and gestational age at ECV, type of breech, mode of delivery and scan findings noted down. The numbers of patients who consented and refused the procedure, the numbers of successful ECV and vaginal delivery after successful ECV were noted and the results analysed using SPSS 21 version.

\section{RESULTS}

A total of 669 patients with breech presentation at term were identified in the time period specified and this corresponded to $2.7 \%$ of all deliveries. Amongst these, ECV was done in 256, of which 91 were successful $(35.5 \%)$. Success of the procedure was more in multigravidas $(51.1 \%)$ as compared to nulliparas (26.8\%). The reported success rates of ECV are varied ranging from $30-80 \%$ and our success rates confirms with global standards. $76.9 \%$ of those who had a successful ECV delivered normally and $23.1 \%$ had a caesarean section. There were no major adverse events recorded as a result of the procedure like non reassuring fetal distress mandating emergency caesarean, placental abruption, fetal death or uterine rupture.

\section{DISCUSSION}

In $413(61.7 \%)$ patients, ECV was not done as $79(11.8 \%)$ patients were not willing for the procedure, 130(19.4\%) patients presented in labour or with premature rupture of membranes (PROM) and in 204(30.5\%), it was contraindicated as there were associated obstetric risk factors like medical complications in pregnancy, Bad obstetric history, prolonged infertility, previous LSCS, uterine anomaly, non- reassuring stress test prior to the procedure. Of the 130 patients who presented in labour or with PROM, 9 had consented to ECV but got admitted before the procedure. In the remaining 121(18.1\%), the diagnosis of breech was missed and was picked up only intrapartum. Of these 21 had an assisted breech delivery and the rest opted for an emergency caesarean section. The 21 patients who had an assisted breech delivery were admitted to the labour room either in advanced active stage or second stage. There was no serious neonatal morbidity noted among those who had an assisted breech delivery.

Limitations of this study were being a retrospective study, details like liquor volume (AFI), type of breech, breech engaged or not, placental position were not documented in all the antenatal charts. Hence the reasons for failure of the procedure cannot be commented upon. Being a tertiary care referral centre, a large number of the patients referred had obstetric or medical complications in their antenatal period thereby ECV could not be offered to a vast majority.

\section{CONCLUSION}

ECV is a relatively safe procedure and should be offered to all patients diagnosed with a breech presentation at term provided there are no contraindications for the procedure.

\section{Funding: No funding sources \\ Conflict of interest: None declared \\ Ethical approval: Not required}

\section{REFERENCES}

1. Hickok DE, Gordon DC, Milberg JA, Williams MA, Daling JR. The frequency of breech presentation by gestational age at birth: a large population-based study. Am J Obstet Gynecol. 1992;166(3):851-2.

2. Albrechtsen S, Rasmussen S, Dalaker K, Irgens LM. Reproductive career after breech presentation: 
subsequent pregnancy rates, interpregnancy interval, and recurrence. Obstet Gynecol. 1998;92(3):345-50.

3. Hannah ME, Hannah WJ, Hewson SA, Hodnett ED, Saigal S, Willan AR. Planned caesarean section versus planned vaginal birth for breech presentation at term: a randomised multicentre trial. Term Breech Trial Collaborative Group. Lancet Lond Engl. 2000;356(9239):1375-83.

4. Hofmeyr GJ, Hannah ME. Planned caesarean section for term breech delivery. Cochrane Database Syst Rev. 2003;(3):CD000166.

5. Boucher M, Bujold E, Marquette GP, Vezina Y. The relationship between amniotic fluid index and successful external cephalic version: a 14-year experience. Am J Obstet Gynecol. 2003;189(3):751-4.

6. Kew N, DuPlessis J, La Paglia D, Williams K. Predictors of cephalic vaginal delivery following external cephalic version: an eight-year single-centre study of 447 cases. Obstet Gynecol Int. 2017;2017:3028398.

7. Obeidat N, Lataifeh I, Al-Khateeb M, Zayed F, Khriesat W, Amarin Z. Factors associated with the success of external cephalic version (ECV) of breech presentation at term. Clin Exp Obstet Gynecol. 2011;38(4):386-9.

Cite this article as: David L, Abraham A, Navaneethan P, Regi A. Breech presentation at term: outcomes and mode of delivery in a tertiary care teaching hospital In South India. Int J Reprod Contracept Obstet Gynecol 2019;8:4111-3. 